\title{
Tamanho inicial e grau de desfolhação do perfilho como determinantes da morfogênese do capim-braquiária
}

\author{
Manoel Eduardo Rozalino Santos ${ }^{1 *}$, Jessica Abreu de Sá Medica ${ }^{1}$, \\ Bruno Humberto Rezende Carvalho ${ }^{1}$, Kathleen Alves Vasconcelos ${ }^{1}$, \\ Gustavo Jordan da Silva Queiroz ${ }^{1}$, Gabriel de Oliveira Rocha', \\ Larissa Lais Santos do Carmo ${ }^{1}$, Dilermando Miranda da Fonseca ${ }^{2}$
}

\begin{abstract}
RESUMO
Objetivou-se, neste artigo, avaliar a morfogênese da Brachiaria decumbens cv. Basilisk syn. Urochloa decumbens cv. Basilisk em perfilhos com pseudocolmo de dois tamanhos iniciais $(5,0 \pm 0,6 \mathrm{~cm}$ ou $12,0 \pm 0,9 \mathrm{~cm})$, e em perfilhos com graus de desfolhação variáveis (sem desfolhação, $50 \%$ de desfolhação e $100 \%$ de desfolhação). A taxa de senescência foliar e a duração de vida da folha foram, respectivamente, de $81 \%$ e $22 \%$ superiores no perfilho com pseudocolmo inicial de $12 \mathrm{~cm}$, quando comparado ao de 5 $\mathrm{cm}$. Os comprimentos do pseudocolmo e da lâmina foliar e os números de folhas expandidas e vivas foram maiores no perfilho com pseudocolmo de $12 \mathrm{~cm}$. Os perfilhos com $100 \%$ de desfolhação apresentaram inferiores taxas de alongamento de colmo, aparecimento e alongamento foliar, comprimento de colmo, e números de folhas expandidas, vivas e mortas em relação aos demais perfilhos avaliados. $O$ incremento do tamanho de perfilhos de $B$. decumbens syn. $U$. decumbens resulta em maior número de folhas e comprimento de seus órgãos. O crescimento foliar e de colmo da $B$. decumbens syn. $U$. decumbens é reduzido com a desfolhação.
\end{abstract}

Palavras-chave: lotação contínua, pastejo, período das águas.

$$
* * *
$$

\section{Introdução}

O estudo de morfogênese de plantas forrageiras é importante para a compreensão da adaptação da planta ao ambiente e ao pastejo. Todavia, em grande parte desses trabalhos, poucas informações foram apresentadas

\footnotetext{
${ }^{1}$ Faculdade de Medicina Veterinária, Universidade Federal de Uberlândia.

2 Departamento de Zootecnia, Universidade Federal de Viçosa.

* Corresponding author: e-mail para contato: manoel.rozalino@ufu.br Av. Pará, 1720, Bloco 2T, Campus Umuarama, Uberlândia, MG, Cep: 38400-902.
} 
sobre as características dos perfilhos inicialmente marcados. Nesse contexto, é possível que a escolha de perfilhos com distintas características no início das avaliações, tal como tamanhos diferentes, possa influenciar nos resultados obtidos, o que necessita ser mais bem investigado.

Outro aspecto importante e que modifica a morfogênese da planta forrageira é a intensidade de desfolhação. Esta resulta em aumento da incidência de luz na base das plantas, o que estimula o perfilhamento (PACIULLO et al., 2008); em economia de água devido à diminuição da relação parte aérea/raiz; em aumento do status nutricional dos tecidos remanescentes em curto prazo; e em incremento na diversidade de perfilhos no pasto (SANTOS et al., 2011).

Por outro lado, a desfolhação intensa pode causar redução da área foliar e da interceptação de luz pela planta, o que diminui a fotossíntese e o crescimento do pasto (TAIZ E ZEIGER, 2006), causando decréscimo na participação relativa das lâminas foliares de maior capacidade fotossintética (BRAGA et al., 2009)) e comprometendo o crescimento radicular (CRUCH et al., 2002). Desse modo, é relevante avaliar os efeitos do grau de desfolhação sobre a dinâmica de desenvolvimento das plantas forrageiras.

Assim, este trabalho foi desenvolvido com o objetivo de avaliar as características morfogênicas e estruturais em perfilhos de B. decumbens cv. Basilisk com dois comprimentos iniciais de pseudocolmo e com três graus de desfolhação iniciais.

\section{Material e métodos}

Este trabalho foi conduzido de setembro a dezembro de 2009 numa pastagem de Brachiaria decumbens cv. Basilisk Stapf. (capim-braquiária) estabelecida em 1997, pertencente ao Setor de Forragicultura do Departamento de Zootecnia da Universidade Federal de Viçosa, em ViçosaMG (204 $\left.45^{\prime} \mathrm{S} ; 42^{\circ} 51^{\prime} \mathrm{W} ; 651 \mathrm{~m}\right)$. A área experimental foi constituída de três 
piquetes (unidades experimentais) de aproximadamente 0,30 ha cada, além de uma área reserva. A análise química do solo, realizada no início do período experimental, na camada $0-20 \mathrm{~cm}$, apresentou os seguintes resultados: $\mathrm{pH}$ em $\mathrm{H}_{2} \mathrm{O}: 5,1$; P: 2,9 (Mehlich-1) e K: 85 mg.dm-3; $\mathrm{Ca}^{2+}$ : 2,05; $\mathrm{Mg}^{2+}$ : 0,45; $\mathrm{Al}^{3+}:$ 0,19 cmolc. $_{\mathrm{c}} \cdot \mathrm{dm}^{-3}(\mathrm{KCl} 1 \mathrm{~mol} / \mathrm{L})$; CTC: 5,1 $\mathrm{cmol}_{\mathrm{c}} \cdot \mathrm{dm}^{-3}$; P-rem: 11,02 mg.L.1; e matéria orgânica: 48,2 g.dm ${ }^{-3}$. Durante o experimento, os dados climáticos foram registrados (Tabela 1).

Tabela 1. Médias mensais da temperatura média diária, insolação, precipitação pluvial total mensal e evaporação total mensal durante os períodos de setembro a dezembro de 2009

\begin{tabular}{|c|c|c|c|c|c|c|}
\hline Mês & $\begin{array}{l}\text { Temperatura } \\
\text { do ar }\left({ }^{\circ} \mathrm{C}\right)\end{array}$ & média & $\begin{array}{l}\text { Insolação } \\
\text { (horas/dia) }\end{array}$ & $\begin{array}{l}\text { Precipitação } \\
(\mathrm{mm})\end{array}$ & pluvial & $\begin{array}{l}\text { Evaporação } \\
(\mathrm{mm})\end{array}$ \\
\hline Setembro & 21,1 & & 4,9 & 72,2 & & 86,8 \\
\hline Outubro & 21,7 & & 3,8 & 127,9 & & 68,7 \\
\hline Novembro & 23,1 & & 5,6 & 131,5 & & 85,1 \\
\hline Dezembro & 22,4 & & 3,2 & 333,1 & & 58,5 \\
\hline
\end{tabular}

As adubações dos pastos foram efetuadas previamente a este experimento. A adubação fosfatada foi efetuada em janeiro de 2009, com a aplicação de $70 \mathrm{~kg} \cdot \mathrm{ha}^{-1}$ de $\mathrm{P}_{2} \mathrm{O}_{5}$, na forma de superfosfato simples, em toda a área experimental. A adubação nitrogenada, na forma de ureia, foi realizada em três aplicações de $50 \mathrm{~kg} / \mathrm{ha}$ de $\mathrm{N}$ ao final da tarde de cada data de aplicação (16/1/2009, 26/2/2009 e 7/4/2009).

Entre os meses de outubro a dezembro de 2009, foram realizados dois experimentos concomitantes, porém de forma separada na mesma área experimental, na qual os piquetes foram manejados sob lotação contínua, com bovinos, para manter a altura do pasto em $25 \mathrm{~cm}$. No primeiro experimento, de 22/9/2009 a 21/12/2009, foram avaliados perfilhos de uma mesma touceira com dois tamanhos iniciais e no mesmo pasto de capimbraquiária, quais sejam: perfilho com pseudocolmo médio de 5,0 \pm 0,6 cm e perfilho com pseudocolmo médio de $12,0 \pm 0,9 \mathrm{~cm}$. Os primeiros apresentavam cerca de duas ou três folhas vivas, enquanto os últimos 
possuíam aproximadamente quatro ou cinco folhas vivas. As avaliações ocorreram em três áreas por piquete onde as plantas estavam com $25 \mathrm{~cm}$ de altura. Em cada área, foram marcados 16 perfilhos com anel plástico colorido, sendo oito perfilhos de cada tamanho inicial. Em cada área em que ocorreu a avaliação morfogênica, os perfilhos marcados cresceram protegidos do pastejo, devido à utilização de gaiolas teladas de 1,5 x 1,0 x 1,5 m. Foram avaliados três ciclos de coleta de dados de, no mínimo, quatro semanas. Em cada ciclo, um novo grupo de perfilhos foi selecionado para avaliação. Adotou-se o delineamento em blocos ao acaso com seis repetições ou blocos. Os três piquetes da área experimental corresponderam a três blocos, e os três ciclos de avaliação consistiram nos outros três blocos, totalizando seis blocos.

Com uma régua, foi medido o comprimento das lâminas foliares e do pseudocolmo dos perfilhos, duas vezes por semana. Com base nessas informações e de acordo com a metodologia descrita por Paciullo et al. (2008), foram calculadas as variáveis: taxa de aparecimento foliar; filocrono; taxa de alongamento foliar; taxa de alongamento de colmo; duração de vida da folha; taxa de senescência foliar; número de folhas em expansão por perfilho; número de folhas expandidas por perfilho; número de folha viva por perfilho; número de folha morta por perfilho; comprimento da lâmina foliar; e comprimento do pseudocolmo.

No segundo experimento, realizado de 23/9/2009 a 22/12/2009, nos mesmos três piquetes do primeiro experimento, foram avaliados perfilhos com diferentes graus de desfolhação, quais sejam:

- perfilho sem desfolhação: perfilho sem remoção de seus tecidos foliares;

- perfilho com 50\% de desfolhação: perfilho com remoção, no primeiro dia de avaliação, da metade do comprimento de todas as suas lâminas foliares expandidas; 
- perfilho com $100 \%$ de desfolhação: perfilho com remoção total, no primeiro dia de avaliação, de todas as suas lâminas foliares expandidas.

Apenas perfilhos com cerca de duas a três folhas expandidas foram marcados com anel plástico colorido. Em todos os perfilhos desfolhados, a lâmina foliar em expansão permaneceu intacta, sem desfolhação. Os perfilhos foram marcados em três áreas representativas do pasto $(25 \mathrm{~cm})$ de cada piquete, formando-se grupos de nove perfilhos por área, sendo que cada grupo foi constituído de três perfilhos de cada categoria avaliada. Esses perfilhos foram mantidos em crescimento livre, com ausência de pastejo animal, usando-se gaiolas de exclusão do pastejo.

Os perfilhos foram avaliados durante três ciclos de coleta de dados de, no mínimo, quatro semanas, seguindo a mesma metodologia descrita para o primeiro experimento. Nesse segundo experimento, também se adotou o delineamento em blocos ao acaso com seis repetições ou blocos. Os três piquetes da área experimental corresponderam a três blocos, e os três ciclos de avaliação consistiram nos outros três blocos, totalizando seis blocos.

As análises estatísticas dos dados, tanto do primeiro quanto do segundo experimento, foram feitas separadamente e utilizando-se o seguinte modelo estatístico: $Y_{i j}=\mu+B_{j}+T_{i}+e_{i j}$, em que $Y_{i j}$ é a observação referente ao tratamento i no bloco j; $\mu$ é a média geral de todas as observações; $B_{j}$ é o efeito do j-ésimo bloco; $T_{i}$ é o efeito do i-ésimo tratamento; $e_{i j}$ é o erro experimental. Para o primeiro experimento, as médias foram comparadas pelo teste F. Para o segundo, também foi realizada análise de variância e, posteriormente, compararam-se as médias dos perfilhos pelo teste de t. Todas as análises estatísticas foram realizadas ao nível de significância de $10 \%$ de probabilidade. 


\section{Resultados e discussão}

Dentre as características morfogênicas avaliadas, apenas a taxa de senescência foliar (TSeF) e a duração de vida da folha (DVF) foram influenciadas pelo tamanho inicial do pseudocolmo do perfilho (Tabela 2). A TSeF foi cerca de $81 \%$ superior no perfilho com pseudocolmo inicial de 12 $\mathrm{cm}$, quando comparada ao perfilho com pseudocolmo de $5 \mathrm{~cm}$. Da mesma forma, a DVF foi aproximadamente $22 \%$ maior no perfilho com pseudocolmo inicial de $12 \mathrm{~cm}$, quando comparada ao perfilho com pseudocolmo de $5 \mathrm{~cm}$.

Tabela 2. Características morfogênicas do capim-braquiária de acordo com o comprimento inicial do pseudocolmo do perfilho

\begin{tabular}{lllllll}
\hline Comprimento $(\mathrm{cm})$ & TApF & FIL & TAlF & TAlC & TSeF & DVF \\
\hline $5 \pm 0,6$ & 0,115 & 8,7 & 1,76 & 0,48 & $0,16 \mathrm{~b}$ & $27,2 \mathrm{~b}$ \\
$12 \pm 0,9$ & 0,122 & 8,2 & 1,96 & 0,37 & $0,29 \mathrm{a}$ & $34,7 \mathrm{a}$ \\
$P$ valor & 0,1041 & 0,1902 & 0,3170 & 0,2007 & 0,0054 & 0,0319 \\
CV $(\%)$ & 33,0 & 27,9 & 42,7 & 19,8 & 17,7 & 24,0 \\
\hline
\end{tabular}

TApF: taxa de aparecimento foliar (folha.perfilho-1. dia $^{-1}$ ); FIL: filocrono (dia); TAlF: taxa de alongamento foliar (cm.perfilho ${ }^{-1} \cdot$ dia $\left.^{-1}\right)$; TAlC: taxa de alongamento de colmo (cm.perfilho ${ }^{-1}$. dia ${ }^{-1}$ ); TSeF: taxa de senescência foliar (cm.perfilho-1.dia-1); DVF: duração de vida da folha (dia); CV: coeficiente de variação; Médias seguidas de letras distintas na coluna diferem pelo teste $\mathrm{F}(\mathrm{P}<0,10)$.

A maior TSeF no perfilho com pseudocolmo de $12 \mathrm{~cm}$ em relação àquele com $5 \mathrm{~cm}$ (Tabela 2) ocorreu porque o primeiro começou a ser avaliado com maior estádio de desenvolvimento. De fato, no início das avaliações morfogênicas, o primeiro perfilho apresentou cerca de duas ou três folhas vivas, enquanto o segundo perfilho possuía aproximadamente quatro a cinco folhas vivas. Nessa condição, é natural que o perfilho maior e mais desenvolvido apresente maior percentagem de tecidos senescentes.

No que tange à duração de vida da folha, seu maior valor foi verificado no perfilho com $12 \mathrm{~cm}$ de comprimento inicial do pseudocolmo (Tabela 2), o que provavelmente se deve ao maior tamanho inicial de suas lâminas foliares (Tabela 3). Essa assertiva é compreendida quando, de acordo com o critério utilizado neste trabalho, se considera que a folha está 
morta, visto que mais de $50 \%$ do tecido de sua lâmina foliar estava senescente. Dessa forma, quando a folha atingia esse estádio, sua duração de vida findava. Com isso, as lâminas foliares mais compridas nos perfilhos com $12 \mathrm{~cm}$ iniciais de pseudocolmo (Tabela 3), apesar de apresentarem maior taxa de senescência (Tabela 2), possuíam superior quantidade de tecidos e, consequentemente, levaram mais tempo para serem consideradas mortas e, desse modo, apresentaram superior duração de vida (Tabela 2).

A ausência de efeitos do fator estudado para a taxa de aparecimento foliar, filocrono e taxas de alongamento de folha e de colmo (Tabela 2) permite inferir que os perfilhos avaliados tiveram semelhantes taxas de crescimento, provavelmente pelo fato de eles terem sido avaliados em estádio inicial de desenvolvimento muito jovem, a despeito das diferenças em seus tamanhos.

O comprimento médio do pseudocolmo foi maior no perfilho com pseudocolmo inicial de $12 \mathrm{~cm}$ do que naquele com $5 \mathrm{~cm}$ (Tabela 3), o que era esperado em razão do maior tamanho inicial do primeiro.

Tabela 3. Características estruturais do capim-braquiária de acordo com o comprimento inicial do pseudocolmo do perfilho

\begin{tabular}{lllllll} 
Comprimento (cm) & CP & CLF & NFEx & NFEmEx & NFV & NFM \\
\hline $5 \pm 0,6$ & $15,0 \mathrm{~b}$ & $9,6 \mathrm{~b}$ & $3,1 \mathrm{~b}$ & 1,0 & $4,1 \mathrm{~b}$ & 1,3 \\
$12 \pm 0,9$ & $18,7 \mathrm{a}$ & $10,8 \mathrm{a}$ & $4,2 \mathrm{a}$ & 0,9 & $5,1 \mathrm{a}$ & 1,0 \\
$P$ valor & 0,0591 & 0,0001 & 0,0310 & 0,4700 & 0,0509 & 0,3330 \\
$\mathrm{CV}(\%)$ & 44,0 & 28,0 & 17,5 & 12,8 & 15,4 & 38,3 \\
\hline
\end{tabular}

CP: comprimento do pseudocolmo $(\mathrm{cm})$; CLF: comprimento da lâmina foliar $(\mathrm{cm})$; NFEx: número de folha expandida; NFEmEx: número de folha em expansão; NFV: número de folha viva; NFM: número de folha morta; CV: coeficiente de variação; Médias seguidas de letras distintas na coluna diferem pelo teste $\mathrm{F}(\mathrm{P}<0,10)$.

Da mesma forma, o comprimento da lâmina foliar também foi superior no perfilho com pseudocolmo inicial de $12 \mathrm{~cm}$ em relação àquele com $5 \mathrm{~cm}$ (Tabela 3). O maior comprimento do pseudocolmo no perfilho com $12 \mathrm{~cm}$ fez com que as folhas mais novas fizessem maior percurso para se expor, ou seja, a distância percorrida pela folha, desde o ponto de conexão 
com o meristema até a extremidade do pseudocolmo, foi maior, resultando no seu superior comprimento.

Por outro lado, os números de folhas expandidas (NFEx) e vivas (NFV) foram maiores no perfilho com tamanho inicial de $12 \mathrm{~cm}$ do que naquele com $5 \mathrm{~cm}$ (Tabela 3). Esses resultados podem ser justificados pelos maiores NFEx e NFV no início da avaliação (duas a três folhas vivas por perfilho de $5 \mathrm{~cm}$ e quatro a cinco folhas vivas por perfilho de $12 \mathrm{~cm}$ ), bem como pela maior duração de vida da folha (Tabela 2) no perfilho com maior tamanho.

Com relação ao número de folha em expansão (NFEmEx), não houve efeito do fator estudado sobre essa característica (Tabela 3). A ausência de efeito do tamanho inicial do perfilho na taxa de aparecimento foliar do capim-braquiária (Tabela 2) justifica a semelhança do NFEmEx entre os perfilhos avaliados. Os valores de NFEmEx foram similares aos obtidos por Fagundes et al. (2006) e Santos et al. (2010), que verificaram, em média e respectivamente, NFEmEx correspondentes a 1,1 e 1,0 em trabalho com a mesma planta forrageira sob lotação contínua. Dessa forma, existem evidências de que, para a Brachiaria decumbens cv. Basilisk, o valor de NFEmEx é relativamente estável e constante em torno de uma unidade.

O número de folhas mortas (NFM) também não diferiu entre os perfilhos avaliados, o que pode ser decorrente da instabilidade inerente ao processo de senescência, que desencadeia a mortalidade da folha. Neste trabalho, entre as características estruturais avaliadas, o NFM apresentou o coeficiente de variação mais elevado (38,3\%). Além da variabilidade natural, muitas mensurações de NFM resultaram em valores nulos, o que diminuiu a média geral do experimento, resultando em coeficientes de variação muito altos. Em trabalho com a B. decumbens cv. Basilisk sob lotação contínua, com bovinos e durante o período das águas, Santos et al. (2011) verificaram valores de NFM (1,9 a 2,8 folhas por perfilho) superiores aos encontrados neste trabalho (Tabela 3 ). 
No que tange aos efeitos do grau de desfolhação dos perfilhos sobre a morfogênese do capim-braquiária, verificou-se que a taxa de aparecimento foliar (TApF) diferiu entre os graus de desfolhação avaliados, apresentando valores crescentes para os perfilhos com 100\%, 50\% e sem desfolhação, respectivamente. Padrão de resposta contrário ocorreu com o filocrono (Tabela 4).

Tabela 4. Características morfogênicas de perfilhos de capim-braquiária com distintos graus de desfolhação

\begin{tabular}{lllllll}
\hline Grau de desfolhação & TApF & FIL & TAlF & TAlC & TSeF & DVF \\
\hline Sem desfolhação & $0,13 \mathrm{a}$ & $7,7 \mathrm{c}$ & $1,79 \mathrm{a}$ & $0,38 \mathrm{a}$ & $0,28 \mathrm{a}$ & $24,7 \mathrm{~b}$ \\
$50 \%$ & $0,11 \mathrm{~b}$ & $9,5 \mathrm{~b}$ & $1,60 \mathrm{a}$ & $0,39 \mathrm{a}$ & $0,20 \mathrm{ab}$ & $28,7 \mathrm{~b}$ \\
$100 \%$ & $0,09 \mathrm{c}$ & $10,9 \mathrm{a}$ & $1,31 \mathrm{~b}$ & $0,27 \mathrm{~b}$ & $0,09 \mathrm{~b}$ & $34,3 \mathrm{a}$ \\
$P$ valor & 0,0041 & 0,0018 & $<0,0001$ & 0,0677 & 0,0590 & 0,0011 \\
CV (\%) & 26,6 & 24,6 & 13,2 & 18,1 & 39,5 & 40,7 \\
\hline
\end{tabular}

TApF: taxa de aparecimento foliar (folha.perfilho-1.dia ${ }^{-1}$ ); FIL: filocrono (dia); TAlF: taxa de alongamento foliar (cm.perfilho-1.dia-1); TAlC: taxa de alongamento de colmo (cm.perfilho-1 . $^{-1} \mathrm{di}^{-1}$ ); TSeF: taxa de senescência foliar (cm.perfilho-1.dia-1); DVF: duração de vida da folha (dia); CV: coeficiente de variação; Médias seguidas de letras distintas na coluna diferem pelo teste t $(\mathrm{P}<0,10)$.

O aumento no grau de desfolhação no perfilho reduz a área foliar e a interceptação de luz pela planta, o que diminui a fotossíntese e o crescimento do pasto. Em adição, desfolhação intensa compromete o crescimento radicular da gramínea (CRUCH et al., 2012), o que limita a absorção de nutrientes essenciais para a manutenção e o crescimento da planta. Esses fatores podem ter resultado na menor TApF naqueles perfilhos com maior severidade de desfolhação, bem como em inferiores taxas de alongamento de folha (TAlF) e de colmo (TAlC) no perfilho com 100\% de desfolhação em comparação àqueles com 50\% e sem desfolhação (Tabela 4). Corroborando esses resultados, Diavão et al. (2017), ao avaliarem o capim-quicuiu (Pennisetum clandestinum) durante o período de ocupação dos piquetes, também verificaram que a TAlF do perfilho, bem como o acúmulo de forragem, foram menores nas áreas excluídas do pastejo, em relação aos pastos submetidos à desfolhação. 
A remoção de todas as lâminas foliares expandidas do perfilho resulta em menor área foliar, inferior interceptação de luz e, com efeito, em menor taxa fotossintética no perfilho (TAIZ E ZEIGER, 2006). Com isso, é provável que menos fotoassimilados tenham sido disponibilizados para a síntese e o crescimento dos novos órgãos desses perfilhos, o que comprometeu as TAlF e TAlC. Realmente, o carbono fixado pelas folhas pode ser alocado para a utilização no metabolismo celular, fornecendo energia e esqueletos de carbono para a síntese de outros compostos; para a síntese de compostos de transporte, exportados para diversos órgãos drenos da planta; e para a síntese de compostos armazenados, para utilização à noite (TAIZ E ZEIGER, 2006).

A menor TAlC nos perfilhos com 100\% de desfolhação também pode ter sido decorrente da sua menor necessidade de crescimento em altura, pelo fato de esses perfilhos terem apresentado menor número de folha viva e lâmina foliar com menor comprimento final (Tabela 5). Isso pode ter resultado em menor sombreamento ou competição por luz e, com efeito, não foi preciso o perfilho alongar o colmo. Por isso, esse perfilho sem desfolhação também apresentou inferior comprimento do pseudocolmo (Tabela 5).

Por outro lado, a similaridade da TAlF entre perfilhos com 50\% de desfolhação e sem desfolhação (Tabela 4) pode ser explicada por dois mecanismos. Primeiramente, é possível que a remoção da metade do tecido das lâminas foliares expandidas tenha ocasionado o aumento na fotossíntese dos tecidos remanescentes. Adicionalmente, é possível que tenha ocorrido uma distribuição diferencial de fotoassimilados entre os distintos órgãos da planta, de modo que os perfilhos com 50\% de desfolhação tenham se beneficiado, via translocação no floema, com o aporte de compostos orgânicos oriundos dos outros perfilhos com maior área foliar presentes na mesma planta de capim-braquiária.

É válido ressaltar que o curto pseudocolmo dos perfilhos avaliados (Tabela 5) também pode ter propiciado maior proximidade entre o 
meristema apical (órgãos dreno) do perfilho com 50\% de desfolhação e os demais órgãos fontes dos outros perfilhos presentes na mesma planta. Isso favorece o aporte de assimilados para perfilhos desfolhados, porque os órgãos fontes normalmente translocam nutrientes para os órgãos drenos mais próximos (TAIZ E ZEIGER, 2006).

Com relação à taxa de senescência foliar (TSeF), seus valores foram maiores no perfilhos sem desfolhação do que no perfilho com $100 \%$ de desfolhação (Tabela 4). Neste último perfilho, a remoção inicial de todas as lâminas foliares expandidas evitou que, ao término do ciclo de avaliação, essas lâminas estivessem com maior idade e senescessem. Por outro lado, naqueles perfilhos sem desfolhação, parte das lâminas foliares de menor nível de inserção (mais velhas) atingiu o limite de duração de vida e, com efeito, senesceram, o que aumentou a TSeF (Tabela 4). Ademais, como o filocrono foi menor, consequentemente a taxa de aparecimento foliar foi maior no perfilho sem desfolhação (Tabela 4). Com isso, esse perfilho atingiu mais rapidamente o seu número de folha viva. A partir desse estágio, para cada nova folha surgida, uma mais velha senesceu, o que pode ter sido responsável pela maior TSeF do perfilho sem desfolhação, em comparação àquele com $100 \%$ de desfolhação (Tabela 4).

A duração de vida da folha (DVF) no perfilho com $100 \%$ de desfolhação foi maior quando comparada aos demais perfilhos avaliados (Tabela 4). Esse resultado pode estar associado ao mecanismo de compensação da planta, que compensou a sua menor taxa de aparecimento foliar, promovendo a maior duração de vida das suas folhas, o que permitiu a otimização do índice de área foliar da planta.

O comprimento do pseudocolmo foi menor no perfilho com $100 \%$ de desfolhação (Tabela 5). O comprimento da lâmina foliar nos perfilhos com 50 e 100\% de desfolhação também foi inferior quando cotejado com o perfilhos sem desfolhação (Tabela 5). Esses resultados são justificados pelas menores 
taxas de alongamento de folha e de colmo nos perfilhos com desfolhação mais severa (Tabela 4).

Tabela 5. Características estruturais de perfilhos de capim-braquiária com distintos graus de desfolhação

\begin{tabular}{lllllll}
\hline Perfilho & CP & CLF & NFEx & NFEmEx & NFV & NFM \\
\hline Sem desfolhação & $16,3 \mathrm{a}$ & $11,9 \mathrm{a}$ & $3,7 \mathrm{a}$ & 1,0 & $4,7 \mathrm{a}$ & $1,0 \mathrm{a}$ \\
$50 \%$ de desfolhação & $16,0 \mathrm{a}$ & $9,6 \mathrm{~b}$ & $3,6 \mathrm{a}$ & 1,0 & $4,6 \mathrm{a}$ & $1,2 \mathrm{a}$ \\
100\% de desfolhação & $12,6 \mathrm{~b}$ & $10,1 \mathrm{ab}$ & $2,3 \mathrm{~b}$ & 1,0 & $3,3 \mathrm{~b}$ & $0,2 \mathrm{~b}$ \\
$P$ valor & 0,0090 & 0,0064 & 0,0040 & 0,1880 & 0,0003 & 0,0870 \\
CV (\%) & 12,5 & 18,4 & 21,4 & 28,8 & 10,0 & 31,3 \\
\hline
\end{tabular}

CP: comprimento do pseudocolmo $(\mathrm{cm})$; CLF: comprimento da lâmina foliar $(\mathrm{cm})$; NFEx: número de folha expandida; NFEmEx: número de folha em expansão; NFV: número de folha viva; NFM: número de folha morta; CV: coeficiente de variação; Médias seguidas de letras distintas na coluna diferem pelo teste $\mathrm{t}(\mathrm{P}<0,10)$.

O número de folha expandida (NFEx) foi menor no perfilho com 100\% de desfolhação em relação aos perfilhos com 50\% e sem desfolhação (Tabela 5). Esses resultados se devem à menor taxa de aparecimento foliar verificada no perfilho com 100\% de desfolhação (Tabela 4). Contudo, o número de folha em expansão (NFEmEx) não diferiu entre os perfilhos avaliados, o que pode ter ocorrido devido à alta dispersão de seus dados, caracterizada por um coeficiente de variação de 28,8 \% (Tabela 5).

O menor número de folha viva do perfilho com $100 \%$ de desfolhação (Tabela 5) pode ter sido consequência do seu maior filocrono (Tabela 4), isto é, do superior tempo entre o aparecimento de duas folhas consecutivas no perfilho.

O número de folha morta (NFM) também foi inferior no perfilho com $100 \%$ de desfolhação em relação àqueles com 50 \% e sem desfolhação (Tabela 5). A menor taxa de senescência foliar, assim como a maior duração de vida das lâminas foliares dos perfilhos com 100 \% de desfolhação (Tabela 4) explicam esses resultados. 


\title{
4 Conclusão
}

O incremento do tamanho do perfilho de Brachiaria decumbens cv. Basilisk, de 5 para $12 \mathrm{~cm}$, resulta em maior número de folhas e superior comprimento dos órgãos.

O crescimento foliar e de colmo da B. decumbens cv. Basilisk é reduzido com a desfolhação dos perfilhos, o que é compensado pelo aumento da duração de vida da folha.

$$
* * *
$$

\section{Initial size and defeliation level of tiller as a determinants of signalgrass morphogenesis}

\begin{abstract}
This work was conducted to evaluate the morphogenesis of Brachiaria decumbens cv. Basilisk syn. Urochloa decumbens cv. Basilisk in tillers with stem with two initial sizes $(5.0 \pm 0.6 \mathrm{~cm}$ or $12.0 \pm 0.9 \mathrm{~cm})$, and in tillers with varying degrees of defoliation (without defoliation, 50\% defoliation and $100 \%$ defoliation). The leaf senescence rate and leaf lifespan were, respectively, about $81 \%$ and $22 \%$ higher in tiller with $12 \mathrm{~cm}$ initial pseudostem, compared with the one with $5 \mathrm{~cm}$. The stem and leaf lamina lengths and the numbers of expanded and live leaves were higher in tiller with $12 \mathrm{~cm}$ than at $5 \mathrm{~cm}$. The tillers with $100 \%$ defoliation had lower stem elongation, leaf appearance and elongation rates, stem length, and numbers of expanded, live and dead leaves, in relation to other tillers. The increasing of size tillers of $B$. decumbens syn. $U$. decumbens results in greater leaf number and length of their organs. The leaf and stem growths of the $B$. decumbens syn. $U$. decumbens is reduced with defoliation.

Keywords: continuous stocking, grazing, water period.
\end{abstract}

\section{Referências}

BRAGA, G.J.; MELLO, A.C.L.; PEDREIRA, C.G.S.; MEDEIROS, H.L. Fotossíntese e taxa diária de produção de forragem em pastagens de capim-tanzânia sob lotação intermitente. Pesquisa Agropecuária Brasileira, v.44, n.1, p.84-91, 2009. Disponível em: http://www.scielo.br/pdf/pab/v44n1/12.pdf. Acesso em: 13 nov. 2017. https://doi.org/10.1590/S0100-204X2009000100012 
CRUCH, J.R.; OUYANG, L.; EERENS, J.P.; STEWRT, A. The growth of roots of perennial, Italian, hybrid and annual ryegrasses through a high-strength root medium. Grass and Forage Science, v.57, p.322-338, 2002. Disponível em: http://onlinelibrary.wiley.com/doi/10.1046/j.1365-2494.2002.00332.x/abstract. Acesso em: 03 jan. 2018.

DIAVÃO, J.; SCHMITT, D.; NETO MEDEIROS, C.; MARTINS, C.D.M.; SBRISSIA, A.F. Acúmulo de forragem durante o período de ocupação dos animais em pastos sob lotação intermitente. Ciência Animal Brasileira, v.18, p.1-11, 2017. Disponível em: https://www.revistas.ufg.br/vet/article/view/e-41359/22915. Acesso em: 14 dez. 2017.

FAGUNDES, J.A.; FONSECA, D.M.; MISTURA, C.; MORAIS, R.V.; VITOR, C.M.T.; GOMIDE, J.A.; NASCIMENTO JUNIOR, D.; CASAGRANDE, D.R.; COSTA, L.T. Características morfogênicas e estruturais do capim-braquiária em pastagem adubada com nitrogênio avaliadas nas quatro estações do ano. Revista Brasileira de Zootecnia, v.35, p.21-21, 2006. Disponível em: http://www.scielo.br/scielo.php?script=sci arttext\&pid=S1516-35982006000100003. Acesso em: 03 dez. 2018

LEMAIRE, G.; CHAPMAN, D. Tissue Flows in grazed Plant Communities. In: HODGSON, J.; ILLIUS, A.W. The Ecology and Management of Grazing Systems. Inglaterra: Wallingford, p. 3-36, 1996.

PACIULLO, D.S.C.; DERESZ, F.; AROEIRA, L.J.M.; MORENS, M.J.F.; VERNEQUE, R.S. Morfogênese e acúmulo de biomassa foliar em pastagem de capim-elefante avaliada em diferentes épocas do ano. Pesquisa Agropecuária Brasileira, v.43, n.7, p.917-923, 2008. Disponível em: https://seer.sct.embrapa.br/index.php/pab/article/view/6649. Acesso em: 13 nov. 2017.

SANTOS, M.E.R.; FONSECA, D.M.; GOMES, V.M.; PIMENTEL, R.M.; SILVA, G.P.; SILVA, S.P. Caracterização de perfilhos de capim-braquiária em locais com 
três intensidades de pastejo. Revista Brasileira de Saúde e Produção Animal, v.11, p.961-975, 2010. Disponível em: http://revistas.ufba.br/index.php/rbspa/article/viewArticle/1761. Acesso em: 03 dez. 2018.

SANTOS, M.E.R.; FONSECA, D.M.; GOMES, V.M.; SANTOS, A.L.; CASTRO, M.R.S.; ALBINO, R.L. Diversidade de perfilhos em pasto de Brachiaria decumbens manejado em regime de lotação contínua. Boletim de Indústria Animal, v.68, n.1, p.17-26, 2011. Disponível em: vet.org.br/bia/article/view/7199. Acesso em: 26 jan. 2018.

SANTOS, M.E.R.; FONSECA， D.M.; BRAZ， T.G.S.; SILVA， G.P.; GOMES, V.M.; SILVA, S.P. Influência da localização das fezes nas características morfogênicas e estruturais e no acúmulo de forragem em pastos de capimbraquiária. Revista Brasileira de Zootecnia, v. 40, p. 31-38, 2011. Disponível em: http://www.scielo.br/pdf/rbz/v40n1/v40n1a05.pdf. Acesso em: 03 dez. 2018.

TAIZ, L.; ZEIGER, E. Fisiologia Vegetal. 3th ed. Porto Alegre: Artmed; 2006. 